\title{
Article
}

\section{Lack of Salivary Long Non-Coding RNA XIST Expression Is Associated with Increased Risk of Oral Squamous Cell Carcinoma: A Cross-Sectional Study}

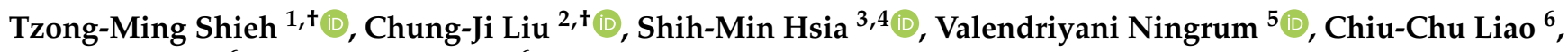 \\ Wan-Chen Lan ${ }^{6}$ and Yin-Hwa Shih ${ }^{6, *}$ \\ 1 School of Dentistry, China Medical University, Taichung 40402, Taiwan; tmshieh@mail.cmu.edu.tw \\ 2 Department of Oral and Maxillofacial Surgery, MacKay Memorial Hospital, Taipei 104217, Taiwan; \\ cjliu@mmh.org.tw \\ 3 School of Nutrition and Health Sciences, Taipei Medical University, Taipei 110301, Taiwan; \\ bryanhsia@tmu.edu.tw \\ 4 Graduate Institute of Metabolism and Obesity Sciences, Taipei Medical University, Taipei 110301, Taiwan \\ 5 School of Dentistry, Baiturrahmah University, by Pass km 15 Aie Pacah, Padang 25586, West Sumatra, \\ Indonesia; valend888@gmail.com \\ 6 Department of Healthcare Administration, Asia University, Taichung 41354, Taiwan; \\ agi-3@yahoo.com.tw (C.-C.L.); magic1986713@hotmail.com (W.-C.L.) \\ * Correspondence: s875008@gmail.com \\ + The authors have equal contribution to this article.
}

\section{check for} updates

Citation: Shieh, T.-M.; Liu, C.-J.; Hsia, S.-M.; Ningrum, V.; Liao, C.-C.; Lan, W.-C.; Shih, Y.-H. Lack of Salivary Long Non-Coding RNA XIST Expression Is Associated with Increased Risk of Oral Squamous Cell Carcinoma: A Cross-Sectional Study. J. Clin. Med. 2021, 10, 4622. https:// doi.org/10.3390/jcm10194622

Academic Editors: Joseph Nissan and Gavriel Chaushu

Received: 25 September 2021

Accepted: 5 October 2021

Published: 8 October 2021

Publisher's Note: MDPI stays neutral with regard to jurisdictional claims in published maps and institutional affiliations.

Copyright: (c) 2021 by the authors. Licensee MDPI, Basel, Switzerland. This article is an open access article distributed under the terms and conditions of the Creative Commons Attribution (CC BY) license (https:// creativecommons.org/licenses/by/ $4.0 /)$.
Abstract: Studies have shown that there is a disparity between males and females in south-east Asia with regard to oral cancer morbidity. A previous study found that oral cancer tissue showed loss of heterozygosity of the X-linked lncRNA XIST gene. We suggest that XIST may play an important role in oral cancer morbidity when associated with sex. Saliva contains proteins and RNAs that are potential biomarkers for the diagnosis of diseases. This study investigated salivary XIST expression and the correlation to clinical-pathological data among oral squamous cell carcinoma patients. Salivary XIST expression was only observed in females, and a high proportion of females with OSCC lack salivary lncRNA XIST expression (88\%). The expression showed no correlation with alcohol consumption, betel quid chewing, or cigarette smoking habits. People lacking salivary lncRNA XIST expression had a significantly increased odds ratio of suffering from OSCC (OR = 19.556, $p<0.001)$, particularly females (OR $=33.733, p<0.001)$. The ROC curve showed that salivary lncRNA XIST expression has acceptable discrimination accuracy to predict the risk of OSCC (AUC $=0.73$, $p<0.01$ ). Lack of salivary lncRNA XIST expression was associated with an increased risk of OSCC. We provided an insight into the role of salivary lncRNA XIST as a biomarker to predict the morbidity of OSCC.

Keywords: long non-coding RNA XIST; oral squamous cell carcinoma; salivary biomarker; morbidity rate

\section{Introduction}

According to global statistics published by the World Health Organization, oral cavity cancer is among the most prevalent types of cancer worldwide, with the female to male incidence ratio showing a discrepancy of 2:1 in south-east Asia [1]. Excessive alcohol consumption, betel quid chewing, and cigarette smoking (ABC habits) are risk factors for oral cancer [2]. However, the $\mathrm{ABC}$ habits cannot explain the increasing trend of young females diagnosed with oral squamous cell carcinoma (OSCC) without performing the $\mathrm{ABC}$ habits [3].

The long non-coding RNA XIST is an X-linked gene that contributes to X-chromosome inactivation. It is also related to tumorigenesis and progression in nasopharyngeal carcinoma [4], small intestinal adenocarcinoma [5], and breast cancer [6]. A previous study 
revealed that a loss of genomic copy number variants of XIST is shown in the OSCC group [7]. Recently, one research article provided evidence of a relationship between XIST and the inhibition of tumor progression in vitro [8]. We suggest that this X-linked gene may be associated with the pathogenesis of oral cancer.

Oral cancer is the sixth leading cause of death in Taiwan in 2020, and the five-year age-standardized relative survival rate is approximately $80 \%$ and $38 \%$ in stage I and IV, respectively [9]. Early detection and intervention for oral cancer are the main strategies to cease cancer progression and elevate the survival rate. Saliva contains a wide variety of RNA types, and more than 4000 distinct coding or non-coding RNA molecules have been identified [10], some of which are biomarkers of oral cancer [11-14]. This study aims to identify whether salivary IncRNA XIST is associated with OSCC pathogenesis, and whether it could be a salivary biomarker of OSCC.

\section{Materials and Methods}

\subsection{Eligibility Criteria}

The ethical approval of this study was reviewed and approved by the institutional review board of the MacKay Memorial Hospital, Taiwan (No. 19MMHIS088e). All of the salivary specimens from OSCC patients and individuals who did not suffer from OSCC were collected in previous studies, and stored in the Department of Medical Research, MacKay Memorial Hospital, Tamsui, Taiwan. The saliva was collected by the spitting method, and handled as described previously [15]. Informed consent was obtained from all subjects. Patient and non-patient subjects' specimens were excluded if GAPDH could not be detected by qPCR.

\subsection{Salivary RNA Extraction}

Salivary RNA was extracted from $200 \mu \mathrm{L}$ of salivary specimens with the PureLink RNA kit (Thermo Fisher Scientific, Waltham, MA, USA). The kit yielded $200 \mu \mathrm{L}$ RNA. We concentrated the sample to $10 \mu \mathrm{L}$ through ethanol precipitation. The RNA samples were stored at $-80^{\circ} \mathrm{C}$ until analysis.

\section{3. $R T-q P C R$}

We used the ReverAid RT reverse transcription kit (Thermo Fisher Scientific, Waltham, MA, USA) and random primers to reverse-transcribe the RNA to cDNA. The primers used for qPCR were designed using the Roche Universal Probe Library (Roche, Basel, Switzerland). qPCR was performed using the Roche LC-480 instrument (Roche, Basel, Switzerland). The reaction conditions were as follows: denaturation at $95^{\circ} \mathrm{C}$ for $10 \mathrm{~min}$ annealing at $60^{\circ} \mathrm{C}$ for $30 \mathrm{~s}$, extension at $72{ }^{\circ} \mathrm{C}$ for $1 \mathrm{~s}$, and for a total run of 60 cycles. For qPCR of GAPDH, we used probe no. 45 , and for XIST, we used probe no. 32. The primer sequences were as follows: GAPDH forward: GAGTCCACTGGCGTCTTCAC; GAPDH reverse: GTTCACACCCATGACGAACA. XIST forward: TCGGAGAAGGATGTCAAAAGA; XIST reverse: TGCAGCGTGGTATCTTCAAT. Electrophoresis of the amplicons was performed using $4 \%$ agarose gels at $100 \mathrm{~V}$.

\subsection{Statistical Analysis}

Statistical analysis of clinical data was conducted using SPSS version 22 software (SPSS Inc., Chicago, IL, USA). The correlation among clinical-pathological data and XIST expression was analyzed by contingency tables, and the significant differences were calculated by Fisher's exact test, with the correlation shown in Phi value. Dummy variables were replaced with categorical variables to conduct binomial regression analysis and ROC curve analysis. The significant differences between groups were defined when $p<0.05$. 


\section{Results}

\subsection{The Characteristics of Participants}

Among the 102 participants, 59 were patients with OSCC (male $n=33$, female $n=26$ ) and 43 were individuals without OSCC (the control group) (male $n=16$, female $n=27)$. The average ages of male and female patients were 53.9 (2.2) and 58.2 (2.3) years old, respectively. The average ages of male and female individuals in the control group were 49.7(2.5) and 39.1(1.3) years old, respectively. Salivary lncRNA XIST was only expressed in females. Among the OSCC group, 35.6\% consumed alcohol, 40.7\% had a betel nut chewing habit, and $52.5 \%$ smoked cigarettes. For primary tumors, $47.5 \%$ of cases were T1-T2, and $52.5 \%$ were T3-T4. Additionally, $50.8 \%, 40.7 \%$, and $8.5 \%$ of tumors were well, moderately, and poorly differentiated, respectively. For clinical stages, $35.6 \%$ of cases were I-II, and $64.4 \%$ were III-IV. Only two patients $(3.4 \%$ ) had distant metastasis. No patients showed tumor recurrence. The tumor sites involved were $28.8 \%$ buccal, $33.9 \%$ tongue, and $37.3 \%$ others, including gingiva, floor of the mouth, mandible, and palate (Table 1).

Table 1. Characteristics of 102 participants.

\begin{tabular}{|c|c|c|}
\hline & $\operatorname{OSCC} n=59$ & Control $n=43$ \\
\hline \multicolumn{3}{|c|}{ Average age, $\mathrm{y}($ mean $\pm \mathrm{SD})$} \\
\hline Male & $53.9 \pm 2.2$ & $49.7 \pm 2.5$ \\
\hline Female & $58.2 \pm 2.3$ & $39.1 \pm 1.3$ \\
\hline Variable & $\mathrm{n}(\%)$ & $\mathrm{n}(\%)$ \\
\hline \multicolumn{3}{|l|}{ Sex } \\
\hline Male & $33(55.9)$ & $16(37.2)$ \\
\hline Female & $26(44.1)$ & $27(62.8)$ \\
\hline \multirow{2}{*}{\multicolumn{3}{|c|}{$\begin{array}{c}\text { Salivary lncRNA XIST } \\
\text { expression }\end{array}$}} \\
\hline & & \\
\hline Male & 0 & $\begin{array}{c}0 \\
22(81 \%)\end{array}$ \\
\hline Female & $3(11 \%)$ & $22(81 \%)$ \\
\hline \multicolumn{2}{|c|}{ Alcohol drinking } & $0(0)$ \\
\hline No & $38(64.4)$ & $43(100)$ \\
\hline \multicolumn{3}{|c|}{ Betel nut chewing } \\
\hline Yes & $24(40.7)$ & $0(0)$ \\
\hline No & $35(59.3)$ & $43(100)$ \\
\hline \multicolumn{3}{|c|}{ Cigarette smoking } \\
\hline Yes & $31(52.5)$ & $0(0)$ \\
\hline No & $28(47.5)$ & $43(100)$ \\
\hline \multicolumn{3}{|c|}{ Primary tumor stage } \\
\hline T1-T2 & $28(47.5)$ & \\
\hline T3-T4 & $31(52.5)$ & \\
\hline \multicolumn{3}{|c|}{ Differentiation } \\
\hline Well & $30(50.8)$ & \\
\hline Moderate & $24(40.7)$ & \\
\hline Poor & $5(8.5)$ & \\
\hline \multicolumn{3}{|c|}{ Clinical stage } \\
\hline I-II & $21(35.6)$ & \\
\hline III-IV & $38(64.4)$ & \\
\hline \multicolumn{3}{|c|}{ Distant metastasis (M) } \\
\hline Yes & $2(3.4)$ & \\
\hline No & $57(96.6)$ & \\
\hline \multicolumn{3}{|l|}{ Recurrence } \\
\hline Yes & $0(0)$ & \\
\hline No & $59(100)$ & \\
\hline \multicolumn{3}{|l|}{ Tumor site } \\
\hline Buccal & $17(28.8)$ & \\
\hline Tongue & $20(33.9)$ & \\
\hline Others & $22(37.3)$ & \\
\hline
\end{tabular}




\subsection{Salivary IncRNA XIST Was Expressed Only in Females}

We conducted a preliminary test to detect XIST expression in buccal cells and saliva, samples of which were kindly provided by four healthy research assistants (two males and two females) in our lab. Of the volunteers, two males and one female did not express XIST in the buccal cells or in the saliva (data shown in Supplementary Figure S1). We further detected XIST expression in salivary specimens collected from OSCC and from individuals in the control group. Salivary lncRNA XIST was only expressed in females, with a high proportion observed in control group females (Table 1, Figure 1). Control group and OSCC males lacked salivary XIST expression with detectable GAPDH amplicons (data shown in Supplementary Figure S2).

(A)

\begin{tabular}{|c|c|c|c|c|c|c|c|c|c|c|c|c|c|c|}
\hline \multirow{2}{*}{$\begin{array}{l}\text { Amplicon } \\
\text { No. }\end{array}$} & \multicolumn{5}{|l|}{$x^{2}$} & $\begin{array}{c}0 \\
0\end{array}$ & \multicolumn{6}{|c|}{ 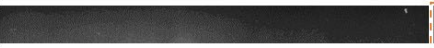 } & -1 & \\
\hline & DI & D2 & & & D4 & D5 & D6 & D7 & D8 & & & D10 & D11 & D12 \\
\hline XIST Ct & 0 & 0 & & & 0 & 29.93 & 0 & 0 & 0 & & & 0 & 31.44 & 0 \\
\hline GAPDH Ct & 28.12 & 29.54 & & & 31.94 & 28.69 & 28.13 & 34.92 & 29.9 & & 37 & 33.32 & 29.04 & 26.63 \\
\hline \multicolumn{15}{|l|}{ Amplicon } \\
\hline No. & D13 & D14 & D15 & D16 & D17 & D18 & D19 & $\mathrm{D} 20$ & D21 & $\mathrm{D} 22$ & D23 & D24 & D25 & $\mathrm{D} 26$ \\
\hline XIST Ct & 0 & 0 & 0 & 0 & 0 & 0 & 0 & 0 & 0 & 0 & 0 & 32.74 & 0 & 0 \\
\hline GAPDH Ct & 32.44 & 35.74 & 30.57 & 33.12 & 29.13 & 32.81 & 29.82 & 0 & 28.33 & 31.59 & 34.23 & $\begin{array}{l:l}3 & 28.68 \\
2\end{array}$ & 31.03 & 34.98 \\
\hline
\end{tabular}

(B)

\begin{tabular}{|c|c|c|c|c|c|c|c|c|c|c|c|c|c|c|c|}
\hline Amplicon & & & $=$ & - & $=$ & $L^{2}$ & $=$ & 政 & 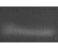 & - & & & $=$ & Sat & \\
\hline No. & N1 & N2 & N3 & N4 & N5 & N6 & N7 & N8 & N9 & N10 & N11 & N12 & N13 & $\mathrm{N} 14$ & N15 \\
\hline XIST Ct & 0 & 0 & 27.58 & 26.97 & 28.03 & 27.92 & 29.05 & 26.75 & 28.53 & 27.13 & 0 & 27.95 & 28.37 & 27.54 & 0 \\
\hline GAPDH Ct & 31.87 & 30.83 & 28.49 & 28.34 & 29.57 & 27.94 & 31 & 28.65 & 30.84 & 28.68 & 30.76 & 28.11 & 30.83 & 26.97 & 30.74 \\
\hline Amplicon & $x^{2}$ & $x=$ & $=$ & rant & $\because$ & $=$ & - & $=$ & & $=$ & - & $\sin$ & & & \\
\hline No. & N16 & N17 & N18 & N19 & $\mathrm{N} 20$ & N21 & $\mathrm{N} 22$ & N23 & N24 & N25 & N26 & N27 & & & \\
\hline XIST Ct & 29.04 & 30.07 & 29.83 & 30.12 & 30.07 & 30.93 & 29.65 & 29.36 & 0 & 30.07 & 30.18 & 30.13 & & & \\
\hline GAPDH Ct & 31.75 & 32.68 & 30.6 & 34.65 & 32.65 & 32.19 & 33.78 & 29.57 & 31.55 & 31.32 & 31.79 & 33.52 & & & \\
\hline
\end{tabular}

Figure 1. The salivary lncRNA XIST expression in female participants: (A) the amplicons and Ct value of XIST and GAPDH among females with OSCC $(n=26)$. The dotted line circles the subjects who express salivary XIST. Only 3 females with OSCC showed positive expression. (B) The amplicons and Ct value of XIST and GAPDH among females without OSCC $(n=27)$. The solid line circles the subject who lacks salivary XIST amplicons. Five control group females showing negative expression.

The grouping gels, which were cropped from different part of the same gel, or from different gels, were shown with a space. The original full-length gels were included in the supplementary files during peer review process.

\subsection{Clinical-Pathological Data Difference between Sex among Patients with OSCC}

Among the patients with OSCC, $83 \%$ (20 of 24) of the smokers, $90.3 \%$ (28 of 31) of those who consumed alcohol, and $95 \%$ ( 20 of 21 ) of those chewed betel nuts were male. Tumors of male patients were low-grade or well differentiated in $66 \%$ (22 of 33) of cases, and most were in the buccal site (13 of 33). A higher proportion of tumors in female patients showed moderate or poor differentiation (17 of 26), and most were on the tongue (14 of 26) (Table 2). Most females with OSCC did not have ABC habits. The tumor was typically small and poorly differentiated when located in the tongue. Most males with OSCC had $\mathrm{ABC}$ habits, and the tumors were typically located in the buccal site, were larger, and well differentiated.

\subsection{Increased Risk of OSCC in Individuals without Salivary lncRNA XIST Expression}

We analyzed the correlation between the clinical-pathological data and XIST expression. Salivary lncRNA XIST expression was correlated with sex (Tables 1 and 3) among all participants, and was correlated with OSCC among female participants (Table 4). Salivary lncRNA XIST expression had no significant correlation with $\mathrm{ABC}$ habits or death. 
We further conducted binomial logistic regression, and found that individuals who did not express XIST had a 19.5-fold higher risk of suffering from OSCC. Females who did not express salivary lncRNA XIST had a 33.7-fold higher risk of suffering from OSCC (Table 5). The ROC analysis showed that, $73 \%$ (acceptable discrimination) of the time, the model would correctly assign a higher absolute OSCC risk to patient with an absence of XIST expression (Figure 2).

Table 2. The significant difference of clinical characteristics between sexes among OSCC patients.

\begin{tabular}{|c|c|c|c|}
\hline \multirow[b]{2}{*}{ Variable } & \multicolumn{2}{|c|}{ Sex } & \multirow[b]{2}{*}{$p$} \\
\hline & $\begin{array}{c}\text { Male } \\
n=33\end{array}$ & $\begin{array}{c}\text { Female } \\
n=26\end{array}$ & \\
\hline \multicolumn{4}{|l|}{ Smoking } \\
\hline Yes & 20 & 4 & $<0.001^{* * *}$ \\
\hline No & 13 & 22 & \\
\hline \multicolumn{4}{|l|}{ Alcohol drinking } \\
\hline Yes & 28 & 3 & $<0.001 * * *$ \\
\hline No & 5 & 23 & \\
\hline \multicolumn{4}{|l|}{ Betel nut chewing } \\
\hline Yes & 20 & 1 & $<0.001^{* * *}$ \\
\hline No & 13 & 25 & \\
\hline \multicolumn{4}{|l|}{ Differentiation } \\
\hline Low grade or well & 22 & 9 & 0.019 * \\
\hline moderate or poor & 11 & 17 & \\
\hline \multicolumn{4}{|l|}{ Diagnosis } \\
\hline Tongue Ca. & 6 & 14 & $0.026^{*}$ \\
\hline Buccal Ca. & 13 & 4 & \\
\hline Gingiva Ca. & 7 & 5 & \\
\hline Others & 7 & 3 & \\
\hline
\end{tabular}

Table 3. The correlation and significant difference between XIST expression and clinical pathological data among OSCC patients.

\begin{tabular}{|c|c|c|c|c|c|c|c|c|c|c|}
\hline \multirow[b]{2}{*}{ XIST expression } & \multicolumn{2}{|c|}{ Sex } & \multicolumn{2}{|c|}{ Alcohol } & \multicolumn{2}{|c|}{ Betel } & \multicolumn{2}{|c|}{ Cigarette } & \multicolumn{2}{|c|}{ Death } \\
\hline & $\mathrm{F}$ & $\mathrm{M}$ & No & Yes & No & Yes & No & Yes & No & Yes \\
\hline Yes & 3 & 0 & 3 & 0 & 3 & 0 & 2 & 1 & 3 & 0 \\
\hline No & 23 & 33 & 25 & 31 & 35 & 21 & 33 & 23 & 38 & 18 \\
\hline $\begin{array}{c}\text { Fishe's exact test } \\
p \text { (two-tailed) }\end{array}$ & \multicolumn{2}{|c|}{0.08} & \multicolumn{2}{|c|}{0.1} & \multicolumn{2}{|c|}{0.546} & \multicolumn{2}{|c|}{1} & \multicolumn{2}{|c|}{0.546} \\
\hline Phi & \multicolumn{2}{|c|}{0.261 * } & \multicolumn{2}{|c|}{0.244} & \multicolumn{2}{|c|}{0.172} & \multicolumn{2}{|c|}{0.035} & \multicolumn{2}{|c|}{0.153} \\
\hline
\end{tabular}

OSCC (male + female, $n=59$ ); F: female, M: male; ${ }^{*} p<0.05$.

Table 4. The XIST expression and the correlation of OSCC among females $(n=53)$.

\begin{tabular}{|c|c|c|c|c|c|c|c|c|}
\hline \multirow[b]{2}{*}{ XIST expression } & \multicolumn{2}{|c|}{ OSCC } & \multicolumn{2}{|c|}{ Alcohol } & \multicolumn{2}{|c|}{ Betel Nut } & \multicolumn{2}{|c|}{ Cigarette } \\
\hline & No & Yes & No & Yes & No & Yes & No & Yes \\
\hline Yes & 22 & 3 & 25 & 0 & 25 & 0 & 24 & 1 \\
\hline No & 5 & 23 & 25 & 3 & 27 & 1 & 25 & 3 \\
\hline $\begin{array}{c}\text { Fisher exact test } \\
p \text { (two-tail) }\end{array}$ & \multicolumn{2}{|c|}{$<0.001$} & \multicolumn{2}{|c|}{0.238} & \multicolumn{2}{|c|}{1} & \multicolumn{2}{|c|}{0.613} \\
\hline Phi & \multicolumn{2}{|c|}{$0.7^{* * *}$} & \multicolumn{2}{|c|}{0.231} & \multicolumn{2}{|c|}{0.131} & \multicolumn{2}{|c|}{0.127} \\
\hline
\end{tabular}

*** $p<0.001$; Control group female, $n=27$; female with OSCC, $n=26$. 
Table 5. Binomial logistic regression of OSCC.

\begin{tabular}{cccccc}
\hline & & B & S.E. & $p$ & OR \\
\hline All Participants & XIST expression & 2.973 & 0.667 & $<0.001$ & 19.556 \\
$n=102$ & constant & -1.992 & 0.615 & 0.001 & 0.136 \\
Female subjects & XIST expression & 3.518 & 0.789 & $<0.001$ & 33.733 \\
$n=53$ & constant & -1.992 & 0.615 & 0.001 & 0.136 \\
\hline
\end{tabular}

Dependent variable: OSCC $(0=$ no $)$; XIST expression: $(0=$ express $)$; OR: odds ratio.

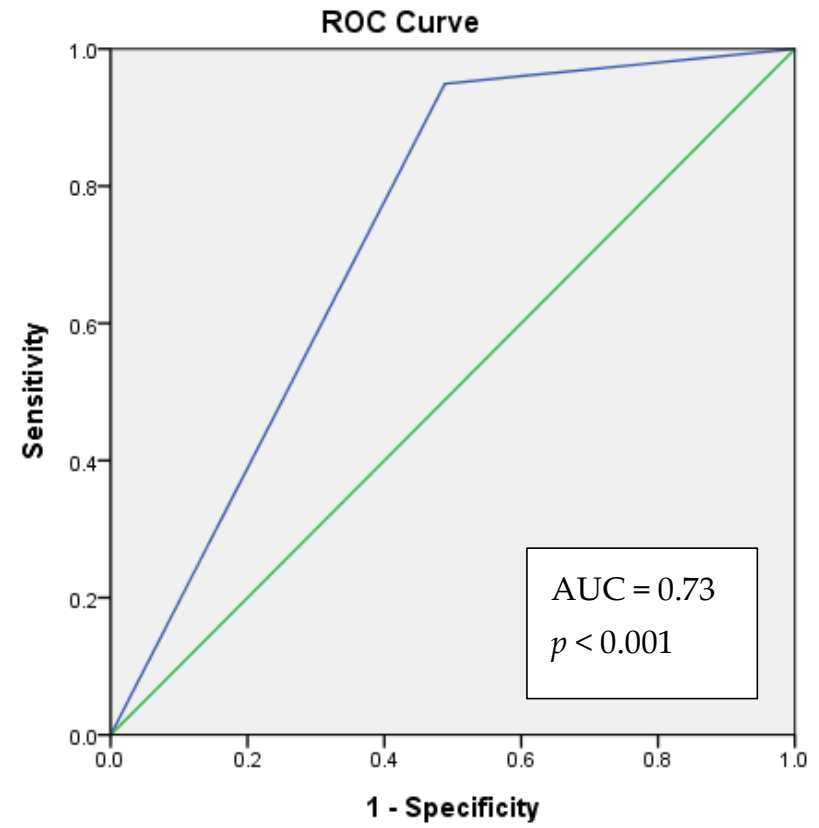

Figure 2. The receiver operating characteristic (ROC) curve analysis of the lack of salivary XIST expression to morbidity prediction of OSCC. Blue line: XIST expression. Green line: reference.

A patient who lacks salivary XIST expression will have a higher predicted OSCC risk score than a patient with salivary XIST expression. The model will correctly assign a higher absolute OSCC risk to a patient with an absence of XIST expression 73\% (acceptable discrimination) of the time.

\section{Discussion}

XIST is a non-coding RNA on the X-chromosome of placental mammals and has a major effect on X-chromosome inactivation. X-chromosome inactivation occurs in males during embryonic development, at the late stage of the first meiotic prophase. However, X-chromosome inactivation persists for the life span of female individuals. One $\mathrm{X}$-chromosome in all female cells undergoes transcriptional inactivation to compensate for the difference in chromosome dosage between sexes [16]. Based on this theory, we evaluated salivary lncRNA XIST expression in all females. Unexpectedly, our data revealed that a large proportion of females with OSCC lacked salivary lncRNA XIST expression (Table 1). These results agree with those of Chang et al. [7], who showed that most patients with oral cancer express lower XIST copy number variants on X-chromosomes.

The concept of Knudson's two-hit hypothesis was challenged after the identification of X-linked tumor suppressor genes, in which the single suppression of $X$-linked tumor suppressor genes caused tumorigenesis. This occurs in several types of tumor, including breast and ovarian cancers [17], sporadic colorectal carcinoma [18], renal cell carcinoma [19], melanoma [20], neuroendocrine tumors [21], and prostate cancer [22]. Regardless of sex, people lacking salivary lncRNA XIST expression had a 19.55-fold increased risk of suffering from OSCC. Females lacking salivary lncRNA XIST had a 33.73-fold increased risk of suffering from OSCC (Table 5). We assumed that the lncRNA XIST played a tumor 
suppressor role in OSCC, due to a lack of expression increasing the morbidity. However, the actual role of lncRNA XIST in oral cancer still needs to be verified by future in vitro and in vivo experiences.

Oral cancer is the sixth leading cancer in Taiwan, with a high prevalence rate in males. Usually, the primary strategy for preventing OSCC is avoiding risk factors such as $\mathrm{ABC}$ habits. The secondary prevention strategy is encouraging people who have been exposed to risk factors to submit to an oral mucosa examination. However, there is an increasing trend for young women diagnosed with OSCC to show no correlation with $\mathrm{ABC}$ risk factors [3]. Their oral health condition is ignored and neglected under the criteria of secondary prevention, causing them to delay seeking medical attention. Although the OSCC morbidity rate is lower in females [23], and is not among the top ten leading causes of cancer-related death in Taiwanese women, public health should still pay attention to this small target group. Our study provided salivary lncRNA XIST as biomarker for secondary prevention for females, similar to risk-stratified cancer screening [24] for breast cancer [25-29]. Research indicates that the HPV virus infection is a risk factor of OSCC among Taiwanese females [30]. Early prediction, prevention, and regular examination strategies for high-risk females can reduce the negative effects of the disease, and result in a better prognosis, survival rate, and quality of life.

This study has several limitations. This was a cross-sectional study design. We enrolled participants and collected salivary samples in an oral surgery clinic as much as possible. Therefore, the average age of the OSCC patient between males and females cannot be well controlled. All the participants in this study were Taiwanese, and the outcome cannot represent all OSCC cases around the world.

\section{Conclusions}

A lack of salivary lncRNA XIST expression is associated with an increased risk of OSCC. ROC analysis reveals that salivary lncRNA XIST expression is an acceptable predictor of the risk of developing OSCC.

Supplementary Materials: The following are available online at https:/ /www.mdpi.com/article/10 $.3390 / \mathrm{jcm} 10194622 / \mathrm{s} 1$, Figure S1: The XIST and GAPDH expression of two normal males and two normal females. Figure S2: The qPCR results of salivary XIST and GAPDH.

Author Contributions: Conceptualization and writing-review and editing, T.-M.S. and Y.-H.S. methodology and investigation, C.-C.L. and W.-C.L. validation, T.-M.S., C.-J.L. resources, C.-J.L. funding acquisition, V.N. and S.-M.H. All authors have read and agreed to the published version of the manuscript.

Funding: This research was funded by grants from the Ministry of Science and Technology, Taiwan (MOST 108-2314-B-468-001) (MOST 109-2314-B-468-006-MY3) and China Medical University (grant no. CMU110-ASIA-14).

Institutional Review Board Statement: The study was conducted according to the guidelines of the Declaration of Helsinki, and approved by the Institutional Review Board of MacKay Memorial Hospital, Taiwan (No. 19MMHIS088e).

Informed Consent Statement: Informed consent was obtained from all subjects involved in the study. Written informed consent has been obtained from the patient(s) to publish this paper" if applicable.

Data Availability Statement: The data that support the findings of this study are available from the corresponding author, [Shih, Y.-H.], upon reasonable request.

Acknowledgments: We thank all participants and research assistants for their contributions to this study.

Conflicts of Interest: The authors declare no conflict of interest. 


\section{References}

1. Mathur, P.T.; Dayal, P.K.; Pai, K.M. Correlation of clinical patterns of oral squamous cell carcinoma with age, site, sex and habits. J. Indian Acad. Oral Med. Radiol. 2011, 23, 81-85. [CrossRef]

2. Petti, S.; Masood, M.; Scully, C. The Magnitude of Tobacco Smoking-Betel Quid Chewing-Alcohol Drinking Interaction Effect on Oral Cancer in South-East Asia. A Meta-Analysis of Observational Studies. PLoS ONE 2013, 8, e78999. [CrossRef] [PubMed]

3. França, D.C.C.; Monti, L.M.; De Castro, A.L.; Soubhia, A.M.P.; Volpato, L.E.R.; De Aguiar, S.M.H.C.; Goiato, M. Unusual Presentation of Oral Squamous Cell Carcinoma in a Young Woman. Sultan Qaboos Univ. Med. J. 2012, 12, 228-231. [CrossRef]

4. Song, P.; Ye, L.-F.; Zhang, C.; Peng, T.; Zhou, X.-H. Long non-coding RNA XIST exerts oncogenic functions in human nasopharyngeal carcinoma by targeting miR-34a-5p. Gene 2016, 592, 8-14. [CrossRef] [PubMed]

5. Shi, Z.; Dragin, N.; Miller, M.L.; Stringer, K.F.; Johansson, E.; Chen, J.; Uno, S.; Gonzalez, F.J.; Rubio, C.A.; Nebert, D.W. Oral benzo[a]pyrene-induced cancer: Two distinct types in different target organs depend on the mouse Cyp1 genotype. Int. J. Cancer 2010, 127, 2334-2350. [CrossRef]

6. Xing, F.; Liu, Y.; Wu, S.-Y.; Wu, K.; Sharma, S.; Mo, Y.-Y.; Feng, J.; Sanders, S.; Jin, G.; Singh, R.; et al. Loss of XIST in Breast Cancer Activates MSN-c-Met and Reprograms Microglia via Exosomal miRNA to Promote Brain Metastasis. Cancer Res. 2018, 78, 4316-4330. [CrossRef] [PubMed]

7. Chen, Y.-J.; Lin, S.-C.; Kao, T.; Chang, C.-S.; Hong, P.-S.; Shieh, T.-M.; Chang, K.-W. Genome-wide profiling of oral squamous cell carcinoma. J. Pathol. 2004, 204, 326-332. [CrossRef]

8. Li, Q.; Sun, Q.; Zhu, B. LncRNA XIST Inhibits the Progression of Oral Squamous Cell Carcinoma via Sponging miR-455-3p/BTG2 Axis. OncoTargets Ther. 2020, 13, 11211-11220. [CrossRef]

9. Chiang, C.-J.; Lo, W.-C.; Yang, Y.-W.; You, S.-L.; Chen, C.-J.; Lai, M.-S. Incidence and survival of adult cancer patients in Taiwan, 2002-2012. J. Formos. Med. Assoc. 2016, 115, 1076-1088. [CrossRef]

10. Spielmann, N.; Ilsley, D.; Gu, J.; Lea, K.; Brockman, J.; Heater, S.; Setterquist, R.; Wong, D.T.W. The Human Salivary RNA Transcriptome Revealed by Massively Parallel Sequencing. Clin. Chem. 2012, 58, 1314-1321. [CrossRef]

11. Bonne, N.J.; Wong, D.T. Salivary biomarker development using genomic, proteomic and metabolomic approaches. Genome Med. 2012, 4, 82. [CrossRef] [PubMed]

12. Ishikawa, S.; Sugimoto, M.; Kitabatake, K.; Sugano, A.; Nakamura, M.; Kaneko, M.; Ota, S.; Hiwatari, K.; Enomoto, A.; Soga, T.; et al. Identification of salivary metabolomic biomarkers for oral cancer screening. Sci. Rep. 2016, 6, 31520. [CrossRef] [PubMed]

13. Shi, T.; Gao, G.; Cao, Y. Long Noncoding RNAs as Novel Biomarkers Have a Promising Future in Cancer Diagnostics. Dis. Markers 2016, 2016, 9085195. [CrossRef] [PubMed]

14. Tang, H.; Wu, Z.; Zhang, J.; Su, B. Salivary lncRNA as a potential marker for oral squamous cell carcinoma diagnosis. Mol. Med. Rep. 2013, 7, 761-766. [CrossRef]

15. Liu, C.-J.; Chen, J.-H.; Hsia, S.-M.; Liao, C.-C.; Chang, H.-W.; Shieh, T.-M.; Shih, Y.-H. Salivary LDOC1 is a gender-difference biomarker of oral squamous cell carcinoma. PeerJ 2019, 7, e6732. [CrossRef]

16. Gardner, R.L.; Lyon, M.F. Biological Sciences: X Chromosome Inactivation studied by Injection of a Single Cell into the Mouse Blastocyst. Nature 1971, 231, 385-386. [CrossRef]

17. Knuutila, S.; Aalto, Y.; Autio, K.; Björkqvist, A.-M.; El-Rifai, W.; Hemmer, S.; Huhta, T.; Kettunen, E.; Kiuru-Kuhlefelt, S.; Larramendy, M.L.; et al. DNA Copy Number Losses in Human Neoplasms. Am. J. Pathol. 1999, 155, 683-694. [CrossRef]

18. Bottarelli, L.; Azzoni, C.; Necchi, F.; Lagrasta, C.; Tamburini, E.; D’Adda, T.; Pizzi, S.; Sarli, L.; Rindi, G.; Bordi, C. Sex Chromosome Alterations Associate with Tumor Progression in Sporadic Colorectal Carcinomas. Clin. Cancer Res. 2007, 13, 4365-4370. [CrossRef]

19. Jiang, F.; Richter, J.; Schraml, P.; Bubendorf, L.; Gasser, T.; Sauter, G.; Mihatsch, M.J.; Moch, H. Chromosomal Imbalances in Papillary Renal Cell Carcinoma: Genetic Differences between Histological Subtypes. Am. J. Pathol. 1998, 153, $1467-1473$. [CrossRef]

20. Indsto, J.O.; Nassif, N.; Kefford, R.; Mann, G.J. Frequent loss of heterozygosity targeting the inactive X chromosome in melanoma. Clin. Cancer Res. 2003, 9.

21. Azzoni, C.; Bottarelli, L.; Pizzi, S.; D’Adda, T.; Rindi, G.; Bordi, C. Xq25 and Xq26 identify the common minimal deletion region in malignant gastroenteropancreatic endocrine carcinomas. Virchows Arch. 2005, 448, 119-126. [CrossRef] [PubMed]

22. Xu, J.; Meyers, D.; Freije, D.; Isaacs, S.; Wiley, K.; Nusskern, D.; Ewing, C.; Wilkens, E.; Bujnovszky, P.; Bova, G.S.; et al. Evidence for a prostate cancer susceptibility locus on the X chromosome. Nat. Genet. 1998, 20, 175-179. [CrossRef] [PubMed]

23. Bray, F.; Ren, J.-S.; Masuyer, E.; Ferlay, J. Global estimates of cancer prevalence for 27 sites in the adult population in 2008. Int. J. Cancer 2013, 132, 1133-1145. [CrossRef] [PubMed]

24. Gierach, G.L.; Choudhury, P.P.; García-Closas, M. Toward Risk-Stratified Breast Cancer Screening: Considerations for Changes in Screening Guidelines. JAMA Oncol. 2020, 6, 31-33. [CrossRef] [PubMed]

25. Parmigiani, G.; Berry, D.A.; Aguilar, O. Determining Carrier Probabilities for Breast Cancer-Susceptibility Genes BRCA1 and BRCA2. Am. J. Hum. Genet. 1998, 62, 145-158. [CrossRef]

26. Tyrer, J.; Duffy, S.W.; Cuzick, J. A breast cancer prediction model incorporating familial and personal risk factors. Stat. Med. 2004, 23, 1111-1130. [CrossRef]

27. Mazzola, E.; Chipman, J.; Cheng, S.-C.; Parmigiani, G. Recent BRCAPRO Upgrades Significantly Improve Calibration. Cancer Epidemiol. Biomark. Prev. 2014, 23, 1689-1695. [CrossRef] 
28. Antoniou, A.C.; Pharoah, P.P.D.; Smith, P.; Easton, D.F. The BOADICEA model of genetic susceptibility to breast and ovarian cancer. Br. J. Cancer 2004, 91, 1580-1590. [CrossRef]

29. Samavarchi Tehrani, S.; Zaboli, E.; Sadeghi, F.; Khafri, S.; Karimian, A.; Rafie, M.; Parsian, H. MicroRNA-26a-5p as a potential predictive factor for determining the effectiveness of trastuzumab therapy in HER-2 positive breast cancer patients. BioMedicine 2021, 11, 6. [CrossRef]

30. Tsai, S.C.S.; Huang, J.Y.; Lin, C.; Liaw, Y.P.; Lin, F.C.F. The association between human papillomavirus infection and head and neck cancer: A population-based cohort study. Medicine 2019, 98, e14436. [CrossRef] [PubMed] 